\title{
Estimation of the intake of anthocyanidins and their food sources in the European Prospective Investigation into Cancer and Nutrition (EPIC) study
}

Raul Zamora-Ros ${ }^{1 *}$, Viktoria Knaze ${ }^{1}$, Leila Luján-Barroso ${ }^{1}$, Nadia Slimani ${ }^{2}$, Isabelle Romieu ${ }^{2}$, Marina Touillaud ${ }^{2}$, Rudolf Kaaks ${ }^{3}$, Birgit Teucher ${ }^{3}$, Amalia Mattiello ${ }^{4}$, Sara Grioni ${ }^{5}$, Francesca Crowe ${ }^{6}$, Heiner Boeing ${ }^{7}$, Jana Förster ${ }^{7}$, J. Ramón Quirós ${ }^{8}$, Esther Molina ${ }^{9,10}$, José María Huerta ${ }^{10,11}$, Dagrun Engeset $^{12}$, Guri Skeie ${ }^{12}$, Antonia Trichopoulou ${ }^{13,14}$, Vardis Dilis ${ }^{13,14}$, Konstantinos Tsiotas ${ }^{13}$, Petra H. M. Peeters ${ }^{15,16}$, Kay-Thee Khaw $^{17}$, Nicholas Wareham ${ }^{18}$, Bas Bueno-de-Mesquita ${ }^{19,20}$, Marga C. Ocké ${ }^{19}$, Anja Olsen ${ }^{21}$, Anne Tjønneland ${ }^{21}$, Rosario Tumino ${ }^{22}$, Gerd Johansson ${ }^{23}$, Ingegerd Johansson $^{24}$, Eva Ardanaz ${ }^{10,25}$, Carlotta Sacerdote ${ }^{26}$, Emily Sonestedt ${ }^{27}$, Ulrika Ericson ${ }^{27}$, Françoise Clavel-Chapelon ${ }^{28,29}$, Marie-Christine Boutron-Ruault ${ }^{28,29}$, Guy Fagherazzi ${ }^{28,29}$, Simonetta Salvini ${ }^{30}$, Pilar Amiano ${ }^{10,31}$, Elio Riboli ${ }^{32}$ and Carlos A. González ${ }^{1}$

${ }^{1}$ Unit of Nutrition, Environment and Cancer, Cancer Epidemiology Research Programme, Catalan Institute of Oncology, IDIBELL, Barcelona, Spain

${ }^{2}$ Dietary Exposure Assessment Group, International Agency for Research on Cancer (IARC), Lyon, France

${ }^{3}$ Department of Cancer Epidemiology, German Cancer Research Centre, Heidelberg, Germany

${ }^{4}$ Department of Clinical and Experimental Medicine, Federico II University, Naples, Italy

${ }^{5}$ Nutritional Epidemiology Unit, Fondazione IRCCS Istituto Nazionale dei Tumori, Milan, Italy

${ }^{6}$ Cancer Epidemiology Unit, University of Oxford, Oxford, UK

${ }^{7}$ Department of Epidemiology, German Institute of Human Nutrition Potsdam-Rehbrücke, Nuthetal, Germany

${ }^{8}$ Public Health and Health Planning Directorate, Asturias, Spain

${ }^{9}$ Andalusian School of Public Health, Granada, Spain

${ }^{10}$ CIBER Epidemiología y Salud Pública (CIBERESP), Spain

${ }^{11}$ Department of Epidemiology, Murcia Regional Health Authority, Murcia, Spain

${ }^{12}$ Department of Community Medicine, University of Tromsø, Tromsø, Norway

${ }^{13}$ WHO Collaborating Centre for Food and Nutrition Policies, Department of Hygiene, Epidemiology and Medical Statistics, University of Athens Medical School, Athens, Greece

${ }^{14}$ Hellenic Health Foundation, Athens, Greece

${ }^{15}$ Julius Centre for Health Sciences and Primary Care, University Medical Centre Utrecht, Utrecht, The Netherlands

${ }^{16}$ Department of Epidemiology and Biostatistics, School of Public Health, Faculty of Medicine, Imperial College, London, UK

${ }^{17}$ University of Cambridge School of Clinical Medicine, Cambridge, UK

${ }^{18}$ MRC Epidemiology Unit, Cambridge, UK

${ }^{19}$ National Institute for Public Health and the Environment (RIVM), Bilthoven, The Netherlands

${ }^{20}$ Department of Gastroenterology and Hepatology, University Medical Centre Utrecht (UMCU), Utrecht, The Netherlands

${ }^{21}$ Institute of Cancer Epidemiology, Danish Cancer Society, Copenhagen, Denmark

${ }^{22}$ Cancer Registry and Histopathology Unit, 'Civile M.P. Arezzo' Hospital, Ragusa, Italy

${ }^{23}$ Department of Clinical Medicine and Public Health/Nutritional Research, Umeå University, Umeå, Sweden

${ }^{24}$ Department of Odontology/Cariology, Umeå University, Umeå, Sweden

${ }^{25}$ Navarre Public Health Institute, Pamplona, Spain

${ }^{26}$ Centre for Cancer Prevention (CPO-Piemonte), and Human Genetic Foundation (HuGeF), Torino, Italy

${ }^{27}$ Diabetes and Cardiovascular Disease, Genetic Epidemiology, Department of Clinical Sciences, Lund University, Malmö, Sweden

${ }^{28}$ INSERM, Centre for Research in Epidemiology and Population Health, U1018, Institut Gustave Roussy, Villejuif, France

${ }^{29}$ Paris South University, UMRS 1018, Villejuif, France

Abbreviations: EPIC, European Prospective Investigation into Cancer and Nutrition; FCDB, food composition database; $24-\mathrm{HDR}$, 24h dietary recall. 


\section{${ }^{30}$ Molecular and Nutritional Epidemiology Unit, Cancer Research and Prevention Institute - ISPO, Florence, Italy \\ ${ }^{31}$ Public Health Department of Guipuzkoa, Instituto Investigación Sanitaria BioDonostia, Basque Government, San Sebastian, Spain \\ ${ }^{32}$ Department of Epidemiology, Public Health and Primary Care, Imperial College, London, UK}

(Received 19 October 2010 - Revised 21 February 2011 - Accepted 24 February 2011 - First published online 12 April 2011)

\section{Abstract}

Anthocyanidins are bioactive flavonoids with potential health-promoting effects. These may vary among single anthocyanidins considering differences in their bioavailability and some of the mechanisms involved. The aim of the present study was to estimate the dietary intake of anthocyanidins, their food sources and the lifestyle factors (sex, age, BMI, smoking status, educational level and physisical activity) involved among twenty-seven centres in ten European countries participating in the European Prospective Investigation into Cancer and Nutrition (EPIC) study. Anthocyanidin intake and their food sources for 36037 subjects, aged between 35 and 74 years, in twentyseven redefined centres were obtained using standardised $24 \mathrm{~h}$ dietary recall software (EPIC-SOFT). An $a d$ hoc food composition database on anthocyanidins (cyanidin, delphinidin, malvidin, pelargonidin, peonidin, petunidin) was compiled using data from the US Department of Agriculture and Phenol-Explorer databases and was expanded by adding recipes, estimated values and cooking factors. For men, the total anthocyanidin mean intake ranged from 19.83 (SE 1.53) $\mathrm{mg} / \mathrm{d}$ (Bilthoven, The Netherlands) to $64 \cdot 88$ (SE 1.86) $\mathrm{mg} / \mathrm{d}$ (Turin, Italy), whereas for women the range was 18.73 (SE 2.80) $\mathrm{mg} / \mathrm{d}$ (Granada, Spain) to 44.08 (SE 2.45) $\mathrm{mg} / \mathrm{d}$ (Turin, Italy). A clear south to north gradient intake was observed. Cyanidins and malvidins were the main anthocynidin contributors depending on the region and sex. Anthocyanidin intake was higher in non-obese older females, non-smokers, and increased with educational level and physical activity. The major food sources were fruits, wine, non-alcoholic beverages and some vegetables. The present study shows differences in both total and individual anthocyanidin intakes and various lifestyle factors throughout Europe, with some geographical variability in their food sources.

\section{Key words: Anthocyanidins: Intake: Food sources: EPIC-Europe}

Anthocyanidins are water-soluble plant pigments that form one subgroup of flavonoids. They mainly provide the red, blue and purple colours to fruits, vegetables and flowers. Chemically, they are derivative salts of the flavilium cation. Anthocyanins are glycosides of anthocyanidins, and their sugar moiety (glucose, galactose, rhamnose, xylose and fructose) is mostly bounded to the $\mathrm{C} 3$ position of the C-ring ${ }^{(1)}$. Diglycosides have also been reported, but in smaller amounts ${ }^{(1)}$.

In nature, more than 500 anthocyanins derived from thirtyone anthocyanidins have been identified ${ }^{(2)}$. However, only six anthocyanidins (cyanidin, delphinidin, malvidin, pelargonidin, peonidin and petunidin) occur ubiquitously and have dietary importance. They are found in fruits, such as berries, red grapes, cherries, and plums; in vegetables, such as red cabbage, red onions, radish and aubergines; and also in fruit and vegetable products, such as juices and wines ${ }^{(3,4)}$. The anthocyanidin content is enhanced during the ripening process. Moreover, these flavonoids are found mainly in the skin of fruit, except in berries where they are in the skin and flesh ${ }^{(5)}$.

Some epidemiological studies suggest that the consumption of anthocyanidins decreases the risk of total mortality ${ }^{(6)}$ and $\operatorname{CVD}^{(7,8)}$ due, in part, to their antioxidant and anti-inflammatory activities ${ }^{(9)}$. There is also much in vitro and in vivo evidence in animal models about their anti-carcinogenic properties $^{(9,10)}$, but findings in human subjects are still controversial. Anthocyanidin intake has been associated with a decreased risk of some cancers, especially digestive system cancers $^{(11-15)}$, but, in other epidemiological studies, these significant associations were not observed ${ }^{(6,16-25)}$.

All anthocyanidins are poorly absorbed (usually less than $0 \cdot 1 \%$, but up to $5 \%$ has been reported), highly metabolised (more than 65\% is detected in glucuronidated and methylated forms in serum) and rapidly excreted in urine (about $4 \mathrm{~h}$ elimination half-life $)^{(9)}$. Differences in the chemical structure of some anthocyanidins also determine their bioavailability; for example, pelargonidin-3-glucoside has an 8-fold higher apparent absorption rate than cyanidin-3-glucoside ${ }^{(26)}$. In the same way, several activities of anthocyanidins depend on their chemical structure ${ }^{(9)}$. For example, delphynidins and cyanidins are able to inhibit lipopolysaccharide-induced cyclo-oxygenase-2 expression, but pelargonidins, peonidins and malvidins are not ${ }^{(27)}$. For these reasons, further studies are needed, comparing individual anthocyanidin bioavailability and metabolic actions.

To date, there are few population-based descriptive studies of anthocyanidin intake ${ }^{(28,29)}$, especially in European countries $^{(30,31)}$. The previous studies mainly reported associations between anthocyanidins and markers of disease risk. In general, these studies evaluated anthocyanidins as a group rather than exploring individual anthocyanidins; furthermore, main food sources were not reported. The aims of the present study were to estimate the consumption of the six most important anthocyanidins and their main food sources across the ten European countries participating in the European Prospective Investigation into Cancer and Nutrition (EPIC) study and across population subgroups.

\section{Materials and methods}

\section{Study population}

EPIC is an ongoing prospective cohort study designed to investigate the associations between diet, lifestyle and cancer 
throughout ten western European countries: Denmark, France, Germany, Greece, Italy, Norway, Spain, Sweden, The Netherlands and the $\mathrm{UK}^{(32,33)}$. The cohort includes approximately 366000 women and 153000 men, most aged 35-70 years, who were enrolled between 1992 and 2000. Participants were mostly recruited from the general population residing within defined geographical areas, with some exception: women members of a health insurance scheme for state school employees (France); women attending breast cancer screening (Utrecht in The Netherlands and Florence in Italy); mainly blood donors (centres in Italy and Spain); and a cohort consisting predominantly of vegetarians (the 'health-conscious' cohort in Oxford, UK) ${ }^{(33)}$. The initial twenty-three EPIC administrative centres were redefined into twenty-seven geographical regions relevant to the analysis of dietary consumption patterns ${ }^{(34)}$. Of the twenty-seven EPIC centres redefined for dietary analysis, nineteen had both male and female participants, and eight recruited only women (France, Norway, Utrecht in The Netherlands and Naples in Italy).

For calibration purposes, a standardised $24 \mathrm{~h}$ dietary recall (24-HDR) interview was administered to a stratified random sample (36994) by age, sex and centre, and weighted for expected cancer cases in each stratum. A total of 36037 subjects with 24-HDR data were included in this analysis, after exclusion of 941 subjects aged less than 35 years of age or over 74 years because of low participation in these age categories, and sixteen subjects were excluded due to missing FFQ data. Approval for the EPIC study was obtained from all ethical review boards of participating institutions. All participants provided written informed consent.

\section{Dietary and lifestyle information}

The 24-HDR was administered in a face-to-face interview, except in Norway, where it was obtained by telephone interview $^{(35)}$. A computerised interview program (EPIC-SOFT) was developed specifically for the calibration study ${ }^{(36,37)}$. A complete description of the rationale, methodology and population characteristics of the 24-HDR calibration study has been described elsewhere ${ }^{(34)}$. The original diet and health survey from which information used in the present study was obtained had ethical approval from all ethical review boards of participating institutions.

Data on other lifestyle factors, including educational level, anthropometry, physical activity and smoking history, were collected at baseline through standardised questionnaires and clinical examinations, and have been described elsewhere ${ }^{(33,34,38)}$. Data on age, as well as on body weight and height, were self-reported by the participants during the 24-HDR interview. The mean time interval between completion of the baseline questionnaire measures and the 24-HDR interview varied by country, and ranged from $1 \mathrm{~d}$ to 3 years later ${ }^{(34)}$.

\section{Food composition database}

In order to estimate the anthocyanidin (cyanidin, delphynidin, malvidin, pelargonidin, peonidin and petunidin) intake from the 24-HDR, a food composition database (FCDB) was developed, which contained 1877 food items (annex table 1; see supplementary material available online at http://www. journals.cambridge.org/bjn). Anthocyanidins are expressed as anthocyanidin aglycones per $100 \mathrm{mg}$ fresh weight and are calculated as the sum of the available forms (glycosides and aglycones) in the literature.

Our database is based on the US Department of Agriculture (USDA) database ${ }^{(3)}$ and expanded with values from PhenolExplorer ${ }^{(39)}$. Approximately, 5 and $1 \%$ of our database come from USDA and Phenol-Explorer databases, respectively. To date, these two databases are the most complete and updated databases on flavonoids and polyphenols and they evaluate and compile the most worldwide food composition data published. There are no large differences on the anthocyanidin data between the two databases.

One cannot assume that foods that are not in either of the databases do not contain anthocyanidins. Therefore, for our FCDB we calculated estimated values (89\%) including logical zeros (26\%), estimations based on similar food items (15\%), application of retention factors (29\%) and recipes (19\%). First, logical zeros were applied when no anthocyanidins are expected in a food (for example, animal foods or plant foods without colour, because anthocyanidins are plant pigments). Second, estimations based on similar food items were applied when it was possible to extrapolate the composition from one food to another similar one (for example, different varieties of blueberries). Third, when there was no analytical data for cooked food, retention factors were applied. These were 70,35 and $25 \%$ after frying, cooking in a microwave oven, and boiling, respectively ${ }^{(40)}$. Crozier et $a l^{(40)}$ calculated these retention factors for flavonols, but these are quite similar to the average of anthocyanidin retention factors available in the literature by each cooking $\operatorname{method}^{(41-45)}$, although further investigation is needed in this regard. Recipes were applied when it was feasible to deconstruct the food item into a list of available ingredients in our FCDB. Finally, only $4 \%$ of our FCDB had missing values, which are calculated as a zero by default.

\section{Statistical analyses}

Dietary intake data are presented as means (least square means) and standard errors stratified by sex and study centre and ordered according to a geographical south to north gradient. The mean intake data were adjusted for age. The contribution of each food group to the total intake of anthocyanidins was calculated as a percentage. Differences in anthocyanidin intake stratified by sex were also compared according to the categories of age, educational level, smoking status, level of physical activity, BMI and European region (south: all centres in Greece, Spain, Italy and the south of France centre; central: all of France other than the south centre, all centres in Germany, The Netherlands and the UK; north: all centres in Denmark, Sweden and Norway). These models were adjusted for age, region, BMI and energy intake. All models were weighted by season and day of the week of the 24-HDR using generalised linear models to 
Table 1. Adjusted ${ }^{*}$ daily intakes $(\mathrm{mg} / \mathrm{d})$ of total and single anthocyanidins by sex and centre ordered from south to north (Mean values with their standard errors)

\begin{tabular}{|c|c|c|c|c|c|c|c|c|c|c|c|c|c|c|c|c|c|c|c|c|c|c|c|c|c|c|c|c|c|c|}
\hline \multirow[b]{3}{*}{ Country and centre } & \multicolumn{15}{|c|}{ Men } & \multicolumn{15}{|c|}{ Women } \\
\hline & \multirow[b]{2}{*}{$n$} & \multicolumn{2}{|c|}{$\begin{array}{l}\text { Anthocyanidins } \\
\text { (mg/d) }\end{array}$} & \multicolumn{2}{|c|}{$\begin{array}{l}\text { Cyanidin } \\
(\mathrm{mg} / \mathrm{d})\end{array}$} & \multicolumn{2}{|c|}{$\begin{array}{l}\text { Delphinidin } \\
\text { (mg/d) }\end{array}$} & \multicolumn{2}{|c|}{$\begin{array}{l}\text { Malvidin } \\
\text { (mg/d) }\end{array}$} & \multicolumn{2}{|c|}{$\begin{array}{l}\text { Pelargonidin } \\
\text { (mg/d) }\end{array}$} & \multicolumn{2}{|c|}{$\begin{array}{l}\text { Peonidin } \\
\text { (mg/d) }\end{array}$} & \multicolumn{2}{|c|}{$\begin{array}{l}\text { Petunidin } \\
\text { (mg/d) }\end{array}$} & \multirow[b]{2}{*}{$n$} & \multicolumn{2}{|c|}{$\begin{array}{l}\text { Anthocyani- } \\
\text { dins (mg/d) }\end{array}$} & \multicolumn{2}{|c|}{$\begin{array}{l}\text { Cyanidin } \\
\text { (mg/d) }\end{array}$} & \multicolumn{2}{|c|}{$\begin{array}{l}\text { Delphinidin } \\
\text { (mg/d) }\end{array}$} & $\begin{array}{r}\text { Malv } \\
(\mathrm{mg}\end{array}$ & idin & $\begin{array}{l}\text { Pelargo } \\
\text { (mg/ }\end{array}$ & $\begin{array}{l}\text { onidin } \\
\text { /d) }\end{array}$ & $\begin{array}{r}\text { Peon } \\
\text { (mg }\end{array}$ & idin & $\begin{array}{r}\text { Petur } \\
\text { (mg }\end{array}$ & idin \\
\hline & & Mean & SE & Mean & SE & Mean & $\mathrm{SE}$ & Mean & SE & Mean & SE & Mean & $S E$ & Mean & SE & & Mean & SE & Mean & SE & Mean & SE & Mean & SE & Mean & SE & Mean & SE & Mean & SE \\
\hline Greece & 1314 & 37.87 & 1.34 & 14.54 & 0.79 & $2 \cdot 21$ & 0.32 & $17 \cdot 30$ & 0.63 & 0.59 & 0.31 & 2.06 & 0.13 & 1.15 & 0.08 & 1373 & 25.77 & 1.31 & 12.42 & 0.77 & $1 \cdot 28$ & 0.31 & 9.53 & 0.61 & 0.65 & 0.30 & 1.31 & 0.12 & 0.57 & 0.08 \\
\hline $\begin{array}{l}\text { Spain } \\
\text { Granada }\end{array}$ & 214 & 38.50 & 3.31 & 13.92 & 1.95 & 2.38 & 0.79 & 17.21 & 1.55 & 1.08 & 0.76 & $2 \cdot 20$ & 0.31 & 1.71 & 0.20 & 300 & 18.73 & 2.80 & 11.66 & 1.65 & 0.85 & 0.67 & 3.87 & 1.31 & 1.28 & 0.64 & 0.76 & 0.26 & 0.31 & 0.17 \\
\hline Murcia & 243 & 36.46 & 3.11 & 16.73 & 1.83 & 2.09 & 0.74 & 13.60 & 1.46 & 0.91 & 0.71 & 1.64 & 0.29 & 1.48 & 0.18 & 304 & $21 \cdot 40$ & 2.79 & $11 \cdot 17$ & 1.64 & 1.20 & 0.66 & $\begin{array}{l}5.59 \\
5.11\end{array}$ & 1.30 & 2.33 & 0.64 & 0.69 & 0.26 & 0.43 & 0.17 \\
\hline Navarra & 444 & 39.45 & $2 \cdot 30$ & 10.39 & 13.52 & 2.94 & 0.55 & $20 \cdot 20$ & 1.08 & 1.00 & 0.53 & 2.50 & 0.21 & 2.42 & 0.14 & 271 & 22.76 & 2.94 & 9.73 & 1.73 & 0.83 & 0.70 & 8.78 & 1.38 & 1.75 & 0.67 & 1.06 & 0.27 & 0.60 & 0.17 \\
\hline San Sebastian & 490 & 47.49 & 2.19 & 16.00 & 1.29 & 3.25 & 0.52 & 20.93 & 1.03 & 2.26 & 0.50 & 2.47 & 0.20 & 2.58 & 0.13 & 244 & 26.29 & 3.11 & 13.20 & 1.83 & 0.93 & 0.74 & 7.18 & 1.46 & 3.54 & 0.70 & 0.80 & 0.29 & 0.65 & 0.18 \\
\hline Asturias & 386 & 39.55 & 2.47 & 14.76 & 1.45 & 2.27 & 0.59 & $15 \cdot 90$ & $1 \cdot 16$ & 2.59 & 0.56 & 2.08 & 0.23 & 1.96 & 0.15 & 324 & 25.16 & 2.69 & 15.41 & 1.58 & 0.77 & 0.64 & 5.03 & 1.26 & 2.52 & 0.62 & 0.94 & 0.25 & 0.49 & 0.16 \\
\hline taly & & & & & & & & & & & & & & & & & & & & & & & & & & & & & & \\
\hline Ragusa & 168 & 44.39 & 3.74 & 19.53 & $2 \cdot 20$ & 3.05 & 0.89 & 16.85 & 1.75 & 0.97 & 0.85 & $2 \cdot 38$ & 0.35 & 1.60 & 0.22 & 138 & 33.93 & 4.13 & 21.68 & 2.43 & 1.98 & 0.98 & 7.56 & 1.94 & 0.84 & 0.94 & 1.27 & 0.38 & 0.59 & 0.25 \\
\hline Naples & & & & & & & & & & & & & & & & 403 & 27.55 & 2.41 & 15.62 & 1.42 & 1.55 & 0.58 & 6.04 & 1.13 & $2 \cdot 38$ & & 1.40 & & 0.57 & 0.14 \\
\hline Florence & 271 & $44 \cdot 46$ & 2.94 & 19.54 & 1.73 & 2.71 & 0.70 & 16.05 & 1.38 & 2.40 & 0.67 & 2.04 & 0.27 & 1.72 & 0.17 & 784 & 30.29 & 1.73 & 14.03 & 1.02 & 1.47 & 0.41 & 9.56 & 0.81 & 3.03 & 0.40 & 1.41 & 0.16 & 0.80 & 0.10 \\
\hline Turin & 676 & 64.88 & 1.86 & 25.44 & $1 \cdot 10$ & 4.05 & 0.44 & 26.42 & 0.87 & 2.70 & 0.43 & 3.61 & 0.17 & 2.67 & 0.11 & 392 & 44.08 & 2.45 & 23.06 & 1.44 & 2.29 & 0.58 & 11.44 & $1 \cdot 15$ & 4.08 & 0.5 & $2 \cdot 11$ & 0.23 & $1 \cdot 11$ & 0.15 \\
\hline Varese & 327 & 55.48 & 2.68 & 23.12 & 1.58 & $4 \cdot 16$ & 0.64 & $21 \cdot 91$ & 1.26 & 1.07 & 0.61 & 2.79 & 0.25 & 2.43 & 0.16 & 794 & 40.04 & 1.72 & $21 \cdot 16$ & 1.01 & 2.09 & 0.41 & 12.33 & 0.81 & 1.97 & 0.39 & 1.60 & 0.16 & 0.89 & 0.10 \\
\hline France & & & & & & & & & & & & & & & & & & & & & & & & & & & & & & \\
\hline South coast & & & & & & & & & & & & & & & & 620 & 38.42 & 1.95 & 15.86 & 1.15 & $2 \cdot 29$ & 0.46 & 12.55 & 0.91 & 4.59 & 0.45 & 1.98 & 0.18 & 1.15 & 0.12 \\
\hline South & & & & & & & & & & & & & & & & 1425 & $40 \cdot 78$ & 1.28 & 18.56 & $0.7>-7$ & 1.99 & 0.31 & $11 \cdot 40$ & 0. & 5.80 & 29 & 1.98 & 12 & 1.04 & 0.08 \\
\hline North-east & & & & & & & & & & & & & & & & 2059 & $38 \cdot 11$ & 1.07 & $17 \cdot 60$ & 0.63 & $2 \cdot 36$ & 0.26 & 9.77 & 0.50 & 5.58 & 0.24 & 1.80 & 10 & 1.01 & 0.06 \\
\hline North-west & & & & & & & & & & & & & & & & 631 & 32.37 & 1.93 & $15 \cdot 39$ & 1.14 & 1.57 & 0.46 & 7.28 & 0.90 & 5.91 & 0.44 & 1.39 & 0.18 & 0.82 & 0.11 \\
\hline Germany & & & & & & & & & & & & & & & & & & & & & & & & & & & & & & \\
\hline Heidelberg & 1034 & 29.79 & 1.51 & $12 \cdot 31$ & 0.89 & 2.31 & 0.36 & 9.78 & 0.71 & 2.82 & 0.34 & 1.33 & 0.14 & 1.24 & 0.09 & 1087 & 36.02 & 1.48 & $16 \cdot 29$ & 0.87 & 3.31 & 0.35 & 8.66 & 0.70 & 5.33 & 0.34 & 1.29 & 0.14 & 1.14 & 0.09 \\
\hline Potsdam & 1233 & 33.74 & $1 \cdot 38$ & 16.86 & 0.81 & 2.54 & 0.33 & 7.38 & 0.65 & 4.85 & 0.32 & 1.25 & 0.13 & 0.87 & 0.08 & 1061 & 40.80 & 1.49 & 20.61 & 0.88 & 3.41 & 0.36 & 9.02 & 0.70 & 5.06 & 0.34 & 1.61 & 0.14 & 1.08 & 0.09 \\
\hline The Netherlands & & & & & & & & & & & & & & & & & & & & & & & & & & & & & & \\
\hline Bilthoven & 1024 & 19.83 & 1.53 & $9 \cdot 24$ & 0.90 & 2.53 & 0.36 & $4 \cdot 37$ & 0.72 & 2.25 & 0.35 & 0.74 & 0.14 & 0.69 & 0.09 & 1086 & 23.27 & 1.49 & $12 \cdot 37$ & 0.88 & 3.32 & 0.36 & 3.86 & 0.70 & 2.35 & 0.34 & 0.69 & 0.14 & 0.68 & 0.09 \\
\hline Utrecht & & & & & & & & & & & & & & & & 1870 & $24 \cdot 59$ & 1.13 & 12.03 & 0.66 & 2.63 & 0.27 & 4.70 & 0.53 & 3.54 & 0.26 & 0.94 & 0.10 & 0.74 & 0.07 \\
\hline UK & & & & & & & & & & & & & & & & & & & & & & & & & & & & & & \\
\hline General pop & 403 & 21.79 & 2.42 & 7.83 & 1.42 & 1.81 & 0.58 & 6.33 & $1 \cdot 13$ & $2 \cdot 15$ & 0.55 & 2.83 & 0.22 & 0.85 & 0.14 & 571 & 24.07 & 2.03 & 8.31 & 1.19 & 1.39 & 0.48 & 7.67 & 0.95 & 2.76 & 0.46 & 3.18 & 0.19 & 0.75 & 0.12 \\
\hline Heatth-conscious & 113 & 27.82 & 4.56 & 14.60 & 2.68 & 2.41 & 1.09 & $5 \cdot 01$ & $2 \cdot 14$ & 4.20 & 1.04 & 0.83 & 0.42 & 0.76 & 0.27 & 196 & 30.78 & 3.46 & 13.68 & 2.04 & $2 \cdot 26$ & 0.82 & 8.42 & 1.62 & 2.70 & 0.79 & 2.82 & 0.32 & 0.89 & 0.21 \\
\hline Denmark & & & & & & & & & & & & & & & & & & & & & & & & & & & & & & \\
\hline Copenhagen & 1356 & 31.60 & 1.32 & $10 \cdot 16$ & 0.77 & $3 \cdot 35$ & 0.31 & 13.28 & 0.62 & $1 \cdot 29$ & 0.30 & 1.68 & 0.12 & 1.82 & 0.08 & 1484 & $26 \cdot 97$ & $1 \cdot 26$ & $10 \cdot 20$ & 0.74 & 2.56 & 0.30 & $10 \cdot 00$ & 0.59 & 1.58 & 0.29 & $1 \cdot 30$ & 0.12 & 1.33 & 0.08 \\
\hline $\begin{array}{l}\text { Aarhus } \\
\text { SWeden }\end{array}$ & 567 & 28.02 & 2.04 & 11.67 & $1 \cdot 20$ & 2.18 & 0.48 & 9.83 & 0.95 & 1.62 & 0.46 & 1.33 & 0.19 & 1.40 & 0.12 & 510 & $26 \cdot 23$ & 2.15 & $12 \cdot 38$ & $1 \cdot 26$ & $1 \cdot 80$ & 0.51 & 8.52 & 1.01 & $1 \cdot 30$ & 0.49 & $1 \cdot 10$ & 0.20 & $1 \cdot 12$ & 0.13 \\
\hline $\begin{array}{l}\text { Sweden } \\
\text { Malmö }\end{array}$ & 1421 & 20.22 & 1.32 & 6.39 & 0.77 & 4.00 & 0.31 & 5.92 & 0.62 & 1.60 & 0.30 & 0.94 & 0.12 & 1.37 & 0.08 & 1711 & 20.13 & 1.19 & 6.51 & 0.70 & 3.52 & 0.28 & 6.23 & 0.56 & 1.73 & 0.27 & 0.93 & 0.11 & 1.22 & 0.07 \\
\hline Umeå & 1344 & $21 \cdot 24$ & 1.32 & 7.27 & 0.78 & 5.41 & 0.32 & 4.72 & 0.62 & 1.34 & 0.30 & 0.92 & 0.12 & 1.58 & 0.08 & 1574 & 22.26 & 1.22 & 8.55 & 0.72 & 5.77 & 0.29 & 4.40 & 0.57 & 1.37 & 0.28 & 0.82 & 0.11 & 1.36 & 0.07 \\
\hline Norway & & & & & & & & & & & & & & & & & & & & & & & & & & & & & & \\
\hline South and east & & & & & & & & & & & & & & & & 1004 & 27.81 & 1.55 & 9.46 & 0.91 & $4 \cdot 16$ & 0.37 & $9 \cdot 20$ & 0.72 & 2.22 & 0.35 & 1.25 & & 1.53 & 0.09 \\
\hline North and west & & & & & & & & & & & & & & & & 793 & $25 \cdot 31$ & 1.74 & $9 \cdot 32$ & 1.02 & 3.98 & 0.41 & 7.78 & 0.81 & 2.00 & 0.40 & 0.98 & 0.16 & 1.25 & 0.10 \\
\hline
\end{tabular}

*Adjusted for age and weighted by season and day of recall. 
control for different distributions of 24-HDR interviews across seasons and days of the week. All analyses were conducted using SPSS Statistics software (version 17.0; SPSS Inc., Chicago, IL, USA).

\section{Results}

The mean intakes and for single and total anthocyanidins stratified by centre and sex, adjusted for age, and weighted by season and day of the week are shown in Table 1. For men, the total anthocyanidin intake ranged from $19.83 \mathrm{mg} / \mathrm{d}$ (Bilthoven, The Netherlands) to $64.88 \mathrm{mg} / \mathrm{d}$ (Turin, Italy), whereas for women the range was from $18.73 \mathrm{mg} / \mathrm{d}$ (Granada, Spain) to $44.08 \mathrm{mg} / \mathrm{d}$ (Turin, Italy). The main anthocyanidin contributors (Table 2) were malvidin $(42.7 \%$ in men and $29.4 \%$ in women) and cyanidin (38.0\% in men and $49.9 \%$ in women) in the southern region, cyanidin $(45.6 \%$ in men and $46.8 \%$ in women) in the central region, and cyanidin $34.0 \%$ in men and $36.8 \%$ in women) and malvidin $(33.0 \%$ in men and $30.5 \%$ in women) in the northern European region.

Table 3 shows the assessment of the effect of certain lifestyle factors on anthocyanidin intake adjusted for sex, age, BMI and energy intake (where appropriate) and weighted by season and day of the week. In south European countries, men consumed more anthocyanidins than women of these countries, whereas in north European countries, they consumed similar amounts, and in central European countries women ingested greater quantities than men. The difference in intake between the sexes in south European countries was due to malvidin intake which in men was two-fold that of women. A geographical gradient of increasing total anthocyanidin, cyanidin, malvidin and peonidin intakes from north to south Europe was observed. However, there was an inverse regional gradient for delphynidin intake. Older individuals consumed more anthocyanidins, with a maximum intake in those aged 55-64 years. There were positive trends when assessing total anthocyanidin intakes and educational level, smoking status (comparing current $v$. never or former smokers), BMI (obese $v$. normal or overweight) and physical activity.

Table 2. Percentage contribution* of intakes of individual anthocyanidins in the European Prospective Investigation into Cancer and Nutrition (EPIC) cohort by European region and sex

\begin{tabular}{llrrr}
\hline \multirow{2}{*}{ Anthocyanidin } & Sex & \multicolumn{3}{c}{ Region } \\
\cline { 3 - 5 } Cyanidin & South & Central & North \\
\hline \multirow{2}{*}{ Delphinidin } & Women & 38.0 & 45.6 & 34.0 \\
& Men & 6.9 & 46.8 & 36.8 \\
Malvidin & Women & 4.9 & 8.7 & 16.2 \\
& Men & 42.7 & 25.6 & 15.9 \\
Pelargonidin & Women & 29.4 & 23.8 & 33.0 \\
& Men & 3.3 & 12.0 & 5.7 \\
Peonidin & Women & 8.9 & 13.7 & 7.0 \\
& Men & 5.4 & 4.7 & 4.8 \\
Petunidin & Women & 4.6 & 4.7 & 4.3 \\
& Men & 4.2 & 3.3 & 6.3 \\
& Women & 2.3 & 2.8 & 5.4 \\
\hline
\end{tabular}

*Adjusted for age and weighted by season and day of recall.
The main food sources of anthocyanidin intake by European region were also studied (Table 4). The group of fruits, nuts and seeds (mainly non-citrus fruit such as grapes, apples and pears) contributed most of the total anthocyanidin intake. In south, central and north European countries this food group contributed $61 \cdot 2,52.9$ and $38.1 \%$, respectively. Other major food sources were wine (contributions ranged from 14.4 to $24.5 \%$ ), followed by non-alcoholic beverages, such as carbonated, soft and isotonic drinks in northern European countries $(15.8 \%)$ and fruit and vegetable juices in central European countries (13.4\%), and some types of vegetables (ranging from 4.8 to $9.7 \%$ ). The major food sources of cyanidins were fruits and non-alcoholic beverages derived from either fruits and vegetables or carbonated, soft and isotonic drinks. For delphynidins, the main contributors in southern countries were wine, bananas, grapes and fruiting vegetables, mainly aubergine. However, in central and northern countries the richest sources were banana, non-alcoholic beverages, berries and wine. Malvidins were almost exclusively derived from grape and wine products. The main contributors to pelargonidins were berries, followed by root vegetables and dairy products with berries as ingredients. We identified fruits, wine and non-alcoholic beverages (only in the north and central European countries) as the most abundant sources of peonidins and petunidins.

\section{Discussion}

To our knowledge, this is the first study to estimate the intake of anthocyanidins and their main food sources in a large adult European cohort, evaluating differences across ten European countries and the most important determinant factors. The use of a unique FCDB on anthocyanidins and the same methodology in the dietary assessment for the whole cohort provided more comparable results across the countries. The FCDB was compiled at the end of 2009 using the most updated and available worldwide databases ${ }^{(3,39)}$ on flavonoids and polyphenols. Furthermore, our database was expanded with recipes, estimations by food or food group and the application of cooking factors ${ }^{(40)}$. However, the use of different FCDB and different food surveys limits the comparisons between studies.

In men, there were great differences in anthocyanidin intakes across EPIC centres, ranging from $19.83 \mathrm{mg} / \mathrm{d}$ in Bilthoven to $64.88 \mathrm{mg} / \mathrm{d}$ in Turin. Indeed, the south European region had the highest consumption of total anthocyanidins, and the two main individual anthocyanidins (cyanidins and malvidins). Moreover, regional trends of increasing anthocyanidin, cyanidin, malvidin and peonidin intakes from northern to southern countries were also observed. Meanwhile, women from central and southern regions were the highest anthocyanidin consumers. Individuals aged 55-64 years, who had a university degree, non-smokers (former or never smokers), those doing moderate or active physical activity and those that were overweight (BMI 25 to $<30 \mathrm{~kg} / \mathrm{m}^{2}$ ) had the highest anthocyanidin consumption. Part of these differences was due to the differences in the consumption pattern of the major food sources in the European countries. For example, in 
Table 3. Adjusted* daily intakes ( $\mathrm{mg} / \mathrm{d}$ ) of total and single anthocyanidins by sex and selected characteristics (Mean values with their standard errors)

\begin{tabular}{|c|c|c|c|c|c|c|c|c|c|c|c|c|c|c|c|c|c|c|c|c|c|c|}
\hline \multirow[b]{2}{*}{ Stratification variable } & \multirow[b]{2}{*}{$n$} & \multicolumn{3}{|c|}{ Anthocyanidins (mg/d) } & \multicolumn{3}{|c|}{ Cyanidin (mg/d) } & \multicolumn{3}{|c|}{ Delphinidin (mg/d) } & \multicolumn{3}{|c|}{ Malvidin (mg/d) } & \multicolumn{3}{|c|}{ Pelargonidin (mg/d) } & \multicolumn{3}{|c|}{ Peonidin (mg/d) } & \multicolumn{3}{|c|}{ Petunidin (mg/d) } \\
\hline & & Mean & $\mathrm{SE}$ & $P$ & Mean & $\mathrm{SE}$ & $P$ & Mean & $\mathrm{SE}$ & $P$ & Mean & SE & $P$ & Mean & $\mathrm{SE}$ & $P$ & Mean & $\mathrm{SE}$ & $P$ & Mean & $\mathrm{SE}$ & $P$ \\
\hline Sex & & & & $<0.001$ & & & $<0.001$ & & & 0.004 & & & 0.274 & & & $<0.001$ & & & 0.017 & & & 0.016 \\
\hline Male & 13028 & 29.44 & 0.53 & & 12.01 & 0.31 & & $2 \cdot 26$ & 0.13 & & $10 \cdot 27$ & 0.25 & & 2.19 & 0.12 & & 1.49 & 0.05 & & 1.23 & 0.03 & \\
\hline Female & 23009 & 33.52 & 0.39 & & 15.09 & 0.23 & & 2.71 & 0.09 & & 9.94 & 0.18 & & 3.02 & 0.09 & & 1.64 & 0.04 & & 1.13 & 0.02 & \\
\hline European region & & & & $<0.001$ & & & $<0.001$ & & & $<0.001$ & & & $<0.001$ & & & $<0.001$ & & & $<0.001$ & & & $<0.001$ \\
\hline South & 11285 & 37.42 & 0.46 & & $16 \cdot 35$ & 0.27 & & $2 \cdot 11$ & 0.11 & & 13.57 & 0.22 & & $2 \cdot 27$ & 0.11 & & 1.87 & 0.04 & & 1.25 & 0.03 & \\
\hline Central & 12988 & 29.79 & 0.44 & & 13.64 & 0.26 & & 2.48 & 0.11 & & 7.52 & 0.21 & & 3.81 & 0.10 & & 1.41 & 0.04 & & 0.93 & 0.03 & \\
\hline North & 11764 & 23.45 & 0.45 & & $8 \cdot 21$ & 0.27 & & 3.83 & 0.11 & & 7.55 & 0.21 & & 1.40 & 0.10 & & 1.05 & 0.04 & & 1.40 & 0.03 & \\
\hline $\begin{array}{l}\text { Age (non-adjusted for } \\
\text { age) (years) }\end{array}$ & 11104 & 20.40 & 0.45 & $<0.001$ & 0.21 & $0 .<t$ & $<0.001$ & 0.00 & 0.11 & $<0.001$ & 1.00 & $0 . \angle T$ & $<0.001$ & 1.40 & 0.10 & $<0.001$ & 1.05 & 0.04 & 0.049 & 1.40 & 0.00 & $<0.001$ \\
\hline $35-44$ & 3335 & 26.43 & 0.89 & & 11.75 & 0.53 & & 1.99 & 0.21 & & 8.23 & 0.42 & & 2.08 & 0.20 & & 1.40 & 0.08 & & 1.00 & 0.05 & \\
\hline $45-54$ & 12595 & 29.67 & 0.48 & & 12.86 & 0.28 & & 2.14 & 0.12 & & 9.71 & 0.22 & & 2.32 & 0.11 & & 1.52 & 0.04 & & 1.13 & 0.03 & \\
\hline $55-64$ & 14940 & 33.44 & 0.45 & & $14 \cdot 20$ & 0.27 & & 2.76 & 0.11 & & 10.74 & 0.21 & & 2.88 & 0.11 & & 1.62 & 0.04 & & 1.33 & 0.03 & \\
\hline $54-74$ & 5167 & 33.34 & 0.77 & & 14.41 & 0.46 & & 2.85 & 0.18 & & 10.34 & 0.36 & & 2.85 & 0.18 & & 1.63 & 0.07 & & 1.27 & 0.05 & \\
\hline $\mathrm{BMI}\left(\mathrm{kg} / \mathrm{m}^{2}\right)$ & & & & $<0.001$ & & & 0.030 & & & 0.261 & & & 0.002 & & & 0.039 & & & 0.004 & & & 0.009 \\
\hline$<25$ & 16854 & 31.74 & 0.46 & & 13.80 & 0.27 & & 2.55 & 0.11 & & 9.95 & 0.22 & & 2.69 & 0.11 & & 1.53 & 0.04 & & $1 \cdot 21$ & 0.03 & \\
\hline 25 to $<30$ & 13766 & 32.04 & 0.46 & & 13.57 & 0.27 & & 2.49 & 0.11 & & 10.52 & 0.22 & & 2.63 & 0.11 & & 1.65 & 0.04 & & 1.18 & 0.03 & \\
\hline$\geq 30$ & 5417 & 28.82 & 0.70 & & 12.57 & 0.41 & & 2.24 & 0.17 & & 9.29 & 0.33 & & 2.24 & 0.16 & & 1.42 & 0.07 & & 1.07 & 0.04 & \\
\hline Level of schooling & & & & $<0.001$ & & & $<0.001$ & & & 0.010 & & & $<0.001$ & & & 0.027 & & & $<0.001$ & & & $<0.001$ \\
\hline None & 1709 & 23.91 & 1.37 & & 10.00 & 0.81 & & 2.09 & 0.33 & & 6.96 & 0.65 & & $2 \cdot 67$ & 0.32 & & 1.15 & 0.13 & & 1.04 & 0.08 & \\
\hline Primary completed & 10469 & 27.83 & 0.54 & & 12.63 & 0.32 & & $2 \cdot 21$ & 0.13 & & 8.22 & 0.26 & & 2.44 & 0.13 & & 1.33 & 0.05 & & 1.00 & 0.03 & \\
\hline Technical/professional & 8038 & 32.24 & 0.63 & & 13.94 & 0.37 & & 2.45 & 0.15 & & 10.54 & 0.30 & & 2.45 & 0.15 & & 1.66 & 0.06 & & 1.20 & 0.04 & \\
\hline Secondary school & 7152 & 33.99 & 0.63 & & $14 \cdot 30$ & 0.38 & & 2.70 & 0.15 & & 11.42 & 0.30 & & 2.58 & 0.15 & & 1.72 & 0.06 & & 1.26 & 0.04 & \\
\hline University degree & 8155 & $36 \cdot 10$ & 0.60 & & 14.89 & 0.35 & & 2.82 & 0.14 & & 12.20 & 0.28 & & 2.95 & 0.14 & & 1.85 & 0.06 & & 1.39 & 0.04 & \\
\hline Smoking status & & & & 0.020 & & & $<0.001$ & & & 0.336 & & & $<0.001$ & & & 0.181 & & & 0.369 & & & $<0.001$ \\
\hline Never smoker & 17483 & 31.37 & 0.44 & & 14.05 & 0.26 & & 2.39 & 0.11 & & 9.57 & 0.21 & & 2.73 & 0.10 & & 1.53 & 0.04 & & $1 \cdot 10$ & 0.03 & \\
\hline Former smok & 10288 & 32.44 & 0.52 & & 13.62 & 0.31 & & 2.61 & 0.13 & & 10.81 & 0.24 & & 2.52 & 0.12 & & 1.60 & 0.05 & & 1.28 & 0.03 & \\
\hline Current smoker & 7726 & 30.42 & 0.59 & & 12.47 & 0.35 & & 2.50 & 0.14 & & 10.17 & 0.28 & & 2.48 & 0.14 & & 1.60 & 0.06 & & 1.19 & 0.04 & \\
\hline Physical activity & & & & $<0.001$ & & & 0.002 & & & 0.450 & & & $<0.001$ & & & 0.041 & & & 0.066 & & & 0.039 \\
\hline Inactive & 7463 & 29.88 & 0.61 & & 13.33 & 0.37 & & 2.28 & 0.15 & & 9.05 & 0.29 & & 2.58 & 0.14 & & 1.54 & 0.06 & & 1.09 & 0.04 & \\
\hline Moderately inactive & 11969 & 32.05 & 0.50 & & 13.78 & 0.30 & & 2.37 & 0.12 & & 10.37 & 0.23 & & 2.81 & 0.11 & & 1.57 & 0.05 & & $1 \cdot 15$ & 0.03 & \\
\hline Moderately active & 8400 & 33.39 & 0.59 & & 14.05 & 0.35 & & 2.33 & 0.14 & & 11.24 & 0.2 & & 2.84 & 0.13 & & 1.72 & 0.06 & & 1.22 & 0.03 & \\
\hline Active & $\begin{array}{l}8400 \\
6380\end{array}$ & 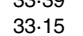 & $\begin{array}{l}0.59 \\
0.67\end{array}$ & & $\begin{array}{l}14.05 \\
15.28\end{array}$ & $\begin{array}{l}0.30 \\
0.40\end{array}$ & & $\begin{array}{l}2.33 \\
2.59\end{array}$ & 0.16 & & 10.11 & $\begin{array}{l}0.27 \\
0.32\end{array}$ & & $\begin{array}{l}2.04 \\
2.39\end{array}$ & $\begin{array}{l}0.13 \\
0.16\end{array}$ & & 1.60 & $\begin{array}{l}0.06 \\
0.06\end{array}$ & & 1.18 & $\begin{array}{l}0.04 \\
0.04\end{array}$ & \\
\hline
\end{tabular}

*Adjusted for sex, age, region, energy intake, and BMI (where appropriate) and weighted by season and day of recall. 
Table 4. Percentage contribution of food groups and some main foods to the intake of total and single anthocyanidins by European region*

\begin{tabular}{|c|c|c|c|c|c|c|c|c|c|c|c|c|c|c|c|c|c|c|c|c|c|}
\hline \multirow[b]{2}{*}{ Food groups and foods $\dagger$} & \multicolumn{3}{|c|}{ Anthocyanidins (\%) } & \multicolumn{3}{|c|}{ Cyanidins (\%) } & \multicolumn{3}{|c|}{ Delphinidins (\%) } & \multicolumn{3}{|c|}{ Malvidins (\%) } & \multicolumn{3}{|c|}{ Pelargonidins (\%) } & \multicolumn{3}{|c|}{ Peonidins (\%) } & \multicolumn{3}{|c|}{ Petunidins (\%) } \\
\hline & South & Central & North & South & Central & North & South & Central & North & South & Central & North & South & Central & North & South & Central & North & South & Central & North \\
\hline Potatoes and other tubers & 0.0 & 0.0 & 0.0 & 0.0 & 0.0 & 0.0 & 0.0 & 0.0 & 0.0 & 0.0 & 0.0 & 0.0 & 0.0 & 0.0 & 0.0 & 0.0 & 0.0 & 0.0 & 0.0 & 0.0 & 0.0 \\
\hline Vegetables & 9.7 & 8.8 & 4.8 & $15 \cdot 2$ & 11.4 & 5.5 & 24.5 & 8.6 & 1.0 & 0.0 & 0.0 & 0.0 & $16 \cdot 7$ & 19.9 & 39.4 & 0.0 & 0.0 & 0.1 & 0.0 & 0.0 & 0.0 \\
\hline Leafy vegetables & 7.1 & 3.8 & 0.4 & $14 \cdot 3$ & 7.8 & $1 \cdot 0$ & 7.0 & 2.5 & 0.1 & 0.0 & 0.0 & 0.0 & 0.0 & 0.0 & 0.1 & 0.0 & 0.0 & 0.0 & 0.0 & 0.0 & 0.0 \\
\hline Fruiting vegetables & 0.9 & 0.4 & 0.1 & 0.0 & 0.0 & 0.0 & 16.7 & 4.9 & 0.5 & 0.0 & 0.0 & 0.0 & 0.1 & 0.0 & 0.0 & 0.0 & 0.0 & 0.0 & 0.0 & 0.0 & 0.0 \\
\hline Root vegetables & 1.2 & 2.8 & 2.7 & 0.0 & 0.0 & 0.0 & 0.0 & 0.0 & 0.0 & 0.0 & 0.0 & 0.0 & $16 \cdot 5$ & 19.8 & 39.2 & 0.0 & 0.0 & 0.0 & 0.0 & 0.0 & 0.0 \\
\hline Cabbages & 0.4 & 1.6 & 1.5 & 0.8 & 3.5 & 4.2 & 0.0 & 0.0 & 0.0 & 0.0 & 0.0 & 0.0 & 0.0 & 0.0 & 0.0 & 0.0 & 0.0 & 0.0 & 0.0 & 0.0 & 0.0 \\
\hline Other and mixed vegetables & 0.1 & 0.1 & 0.1 & 0.1 & 0.1 & 0.2 & 0.7 & 1.2 & 0.4 & 0.0 & 0.0 & 0.0 & 0.1 & 0.0 & 0.1 & 0.0 & 0.0 & 0.1 & 0.0 & 0.0 & 0.0 \\
\hline Legumes & 0.1 & 0.1 & 0.1 & 0.1 & 0.0 & 0.1 & 0.1 & 0.0 & 0.0 & 0.0 & 0.0 & 0.0 & 0.8 & 0.3 & 0.6 & 0.0 & 0.0 & 0.0 & 0.2 & 0.1 & 0.0 \\
\hline Fruits, nuts and seeds & $61 \cdot 2$ & 52.9 & 38.1 & 76.6 & 56.8 & 55.5 & 25.9 & 33.8 & $20 \cdot 2$ & 46.5 & 47.6 & 32.5 & 73.9 & 66.3 & 38.4 & 54.9 & 44.6 & $27 \cdot 7$ & $25 \cdot 8$ & 33.1 & 17.5 \\
\hline Citrus fruits & 0.0 & 0.0 & 0.0 & 0.0 & 0.0 & 0.0 & 0.0 & 0.0 & 0.0 & 0.0 & 0.0 & 0.0 & 0.0 & 0.0 & 0.0 & 0.0 & 0.0 & 0.0 & 0.0 & 0.0 & 0.0 \\
\hline Apples and pears & $14 \cdot 2$ & $10 \cdot 0$ & 12.7 & $30 \cdot 1$ & $21 \cdot 3$ & 34.9 & 0.3 & 0.1 & 0.0 & 0.0 & 0.0 & 0.0 & 0.2 & 0.1 & 0.1 & 0.1 & 0.3 & 0.4 & 0.0 & 0.0 & 0.0 \\
\hline Grapes & 18.9 & 13.0 & 10.6 & 0.9 & 0.7 & 0.7 & $20 \cdot 8$ & 9.4 & 3.7 & $46 \cdot 3$ & 44.5 & 28.0 & 0.1 & 0.0 & 0.1 & 30.3 & 21.7 & 18.5 & $25 \cdot 1$ & 18.5 & 7.7 \\
\hline Stone fruits & 14.8 & 10.0 & 2.8 & $29 \cdot 6$ & 20.0 & 7.6 & 0.0 & 0.0 & 0.0 & 0.0 & 0.0 & 0.0 & 1.5 & 0.6 & 0.1 & $16 \cdot 3$ & 14.1 & 0.8 & 0.0 & 0.0 & 0.0 \\
\hline Berries & 6.3 & 16.5 & 10.1 & 2.6 & 9.6 & 8.3 & $2 \cdot 2$ & 22.5 & $15 \cdot 8$ & 0.1 & 2.9 & 4.2 & 68.1 & 61.5 & 34.5 & 0.4 & $7 \cdot 1$ & 6.1 & 0.6 & $14 \cdot 4$ & 9.7 \\
\hline Other and mixed fruits & 2.5 & 2.3 & $1 \cdot 1$ & 3.5 & 3.2 & 1.4 & 2.6 & 1.7 & 0.5 & 0.0 & 0.0 & 0.0 & 4.0 & 4.1 & 3.7 & 7.8 & 1.5 & 1.8 & 0.1 & 0.2 & 0.1 \\
\hline Olives & 4.5 & 0.8 & 0.9 & $9 \cdot 6$ & 1.7 & 2.5 & 0.0 & 0.0 & 0.0 & 0.0 & 0.0 & 0.0 & 0.0 & 0.0 & 0.0 & 0.0 & 0.0 & 0.0 & 0.0 & 0.0 & 0.0 \\
\hline Nuts and seeds & 0.2 & 0.1 & 0.1 & 0.3 & 0.3 & 0.2 & 0.0 & 0.1 & 0.0 & 0.0 & 0.0 & 0.0 & 0.0 & 0.0 & 0.0 & 0.0 & 0.0 & 0.0 & 0.0 & 0.0 & 0.0 \\
\hline Dairy products & 0.5 & 1.5 & 0.8 & 0.1 & 0.2 & 0.2 & 0.1 & 0.3 & 0.0 & 0.0 & 0.0 & 0.0 & 6.5 & 9.3 & 10.8 & 0.0 & 0.0 & 0.0 & 0.0 & 0.1 & 0.0 \\
\hline Cereal, cakes and confectionery & 1.0 & 6.5 & 4.5 & 1.4 & 7.4 & 6.4 & 1.3 & 19.7 & 3.8 & 0.2 & 2.4 & 2.0 & 1.9 & 2.8 & 3.4 & 1.3 & $5 \cdot 1$ & 7.7 & 0.9 & 9.0 & 6.4 \\
\hline Meat, fish and eggs & 0.0 & 0.0 & 0.0 & 0.0 & 0.0 & 0.0 & 0.0 & 0.0 & 0.0 & 0.0 & 0.0 & 0.0 & 0.0 & 0.0 & 0.0 & 0.0 & 0.0 & 0.0 & 0.0 & 0.0 & 0.0 \\
\hline Non-alcoholic beverages & 1.7 & 13.6 & $19 \cdot 7$ & 3.1 & $21 \cdot 7$ & $26 \cdot 5$ & 0.1 & $16 \cdot 7$ & 49.0 & 0.7 & 3.3 & 0.3 & 0.0 & 0.8 & 5.5 & 0.9 & $21 \cdot 9$ & 7.4 & 0.4 & 7.9 & 19.7 \\
\hline Fruit and vegetable juices & 1.7 & 13.4 & 3.9 & 3.0 & 21.5 & 8.6 & 0.1 & 16.4 & 3.3 & 0.7 & 3.2 & 0.2 & 0.0 & 0.8 & 0.8 & 0.9 & 21.7 & 2.0 & 0.4 & 7.7 & 1.4 \\
\hline $\begin{array}{l}\text { Carbonated, soft, and } \\
\text { isotonic drinks }\end{array}$ & 0.0 & 0.2 & $15 \cdot 8$ & 0.1 & 0.2 & 17.9 & 0.0 & 0.3 & $45 \cdot 8$ & 0.0 & 0.1 & 0.1 & 0.0 & 0.0 & 4.7 & 0.0 & 0.2 & 5.4 & 0.0 & 0.2 & $18 \cdot 3$ \\
\hline Coffee, tea and herbal teas & 0.0 & 0.0 & 0.0 & 0.0 & 0.0 & 0.0 & 0.0 & 0.0 & 0.0 & 0.0 & 0.0 & 0.0 & 0.0 & 0.0 & 0.0 & 0.0 & 0.0 & 0.0 & 0.0 & 0.0 & 0.0 \\
\hline Alcoholic beverages & $25 \cdot 5$ & 15.9 & $25 \cdot 4$ & 3.4 & $2 \cdot 3$ & 4.0 & $47 \cdot 6$ & 19.5 & $15 \cdot 3$ & $52 \cdot 2$ & $45 \cdot 2$ & 55.6 & 0.0 & 0.1 & 0.0 & 42.6 & $27 \cdot 3$ & 46.6 & $72 \cdot 1$ & $47 \cdot 2$ & 39.2 \\
\hline Wine & 24.5 & 14.4 & 24.5 & 2.0 & 1.2 & 2.6 & $45 \cdot 9$ & 17.9 & 15.0 & 51.8 & 42.3 & 55.7 & 0.0 & 0.0 & 0.0 & 42.0 & 25.5 & 45.7 & 70.5 & 44.1 & 38.5 \\
\hline Beer, cider & 0.6 & 0.3 & 0.4 & $1 \cdot 2$ & 0.7 & $1 \cdot 2$ & 0.0 & 0.0 & 0.0 & 0.0 & 0.0 & 0.0 & 0.0 & 0.0 & 0.0 & 0.0 & 0.1 & 0.0 & 0.0 & 0.0 & 0.0 \\
\hline Liqueurs and spirits & 0.4 & 1.2 & 0.5 & 0.2 & 0.4 & 0.2 & 1.7 & 1.6 & 0.3 & 0.5 & 2.9 & 1.0 & 0.0 & 0.1 & 0.0 & 0.6 & 1.8 & 0.8 & 1.6 & 3.1 & 0.7 \\
\hline Soups, bouillons & 0.0 & 0.3 & 5.9 & 0.0 & 0.1 & 1.7 & 0.0 & 0.9 & $10 \cdot 3$ & 0.0 & 0.4 & 7.3 & 0.0 & 0.0 & 0.0 & 0.0 & 0.4 & 9.5 & 0.0 & 1.3 & $16 \cdot 4$ \\
\hline Miscellaneous & 0.3 & 0.5 & 0.7 & 0.2 & 0.1 & 0.2 & 0.4 & 0.5 & 0.4 & 0.4 & 1.0 & $1 \cdot 2$ & 0.2 & 0.6 & 1.8 & 0.3 & 0.6 & $1 \cdot 1$ & 0.5 & $1 \cdot 1$ & 0.8 \\
\hline
\end{tabular}

*Values are percentages derived from models adjusted for age and sex and weighted by season and day of recall. There were differences between European regions for all food sources $(P<0.001)$, except for food sources where anthocyanidin contributions are less than $0.2 \%$ for all regions (NS differences).

†Leafy vegetables include red leaf lettuce, red chicory, radicchio and trevise (red Treviso lettuce); fruiting vegetables include aubergines; root vegetables include beetroot, red radish and black radish; cabbages include red cabbage and Chinese cabbage; stone fruits include plums, peaches, nectarines, apricots, mangoes and paraguayos; other and mixed fruits include cherries, red fruit not specified, sour cherries, persimmon, sharon fruit and pomegranate; cereal, cakes and confectionery include fruit cakes, biscuits with jam and plum cake; fruit and vegetable juices include blackcurrant juice, cranberry juice, redcurrant juice, cherry juice, peach juice, apricot juice, plum juice and beetroot juice; carbonated, soft and isotonic drinks include blackcurrant syrups, syrups of fruits and berries, cherry coke, pommac and jaffa; soups and bouillons include bilberry soup, berry soup and elderberry soup. 
southern countries, a high intake of wine ${ }^{(46)}$, non-citrus fruits (especially grapes, stone fruits, apples and pears, and olives) and leafy vegetables ${ }^{(47)}$ was observed. However, in central and northern countries the main contributors were noncitrus fruits (mainly berries, apples and pears, and grapes), wine and, finally, non-alcoholic beverages (juices and soft drinks of anthocyanidin-rich fruits). The large differences in anthocyanidin intakes between men $(45.47 \mathrm{mg} / \mathrm{d})$ and women $(31.73 \mathrm{mg} / \mathrm{d})$ in the southern region (Italy, Spain, Greece) were due to the high consumption of red wine, which is very rich in malvidins, as observed in a previous Spanish cohort ${ }^{(30)}$. The present results are comparable with previously published data of intakes in the southern European region; median intakes of 9.3 to $28.0 \mathrm{mg} / \mathrm{d}$ have been reported $^{(7,12-15,17,18,21,24,25,48-50)}$ although a Greek cohort was found to consume $52.6 \mathrm{mg} / \mathrm{d}^{(22)}$. Two previous studies in northern countries (Finland) also reported great differences in mean intakes; $5.9 \mathrm{mg} / \mathrm{d}$ in the Kuopio Ischaemic Heart Disease Risk Factor Study ${ }^{(23)}$ and $47 \mathrm{mg} / \mathrm{d}$ in the FINDIET 2002 Study $^{(31)}$. In non-European countries, lower intakes have been observed than in European countries. For example, in the USA mean intakes were found to range from less than 1 to $10 \cdot 1 \mathrm{mg} / \mathrm{d}^{(6,11,16,19,20,29)}$, while in Australia $2 \cdot 9 \mathrm{mg} / \mathrm{d}^{(28)}$, and in Japan $11.3 \mathrm{mg} / \mathrm{d}^{(51)}$ were reported.

Cyanidins were the most prevalent anthocyanidins (34-50\%) except in men from the southern European region. Cyanidin intake ranged from 8.2 to $16.4 \mathrm{mg} / \mathrm{d}$; these values are slightly higher than our previous results in Spain $(6.2 \mathrm{mg} / \mathrm{d})^{(30)}$ and in Greece $(4 \mathrm{mg} / \mathrm{d})^{(50)}$, lower than Finland $(25 \mathrm{mg} / \mathrm{d})^{(31)}$ and much higher than in Australia $(0.42 \mathrm{mg} /$ $\mathrm{d})^{(28)}$. In Finland the main contributors were berries and their derived products $(88 \%)^{(31)}$, whereas in the present study berries and berry products (juices, soft drinks and soups) represented approximately 6, 31 and $37 \%$ in southern, central and northern countries, respectively. In the present study, leafy vegetables, apples and pears, and stone fruits were also major food sources of cyanidins. Malvidin was the main anthocyanidin in men from the southern European region, which is in line with findings from our previous study in Spain ${ }^{(30)}$ and in Australia ${ }^{(28)}$. In the entire cohort and in the literature the main contributors were red wine and red grapes. Delphynidin was usually the third most abundant anthocyanidin (5.6 and $16.0 \%$ in southern and northern countries, respectively). Moreover, a geographical trend was observed, with increasing intakes from south $(0.8 \mathrm{mg} / \mathrm{d}$ women in Navarra, Spain) to north $(5.8 \mathrm{mg} / \mathrm{d}$ women in Umeå, Sweden), as has previously been observed in Spain $(2.5 \mathrm{mg} / \mathrm{d})^{(30)}$ and Finland $(14 \mathrm{mg} / \mathrm{d})^{(31)}$. Pelargonidins $(3 \cdot 3-13 \cdot 7 \%)$, peonidins $(4 \cdot 3-5 \cdot 4 \%)$ and petunidins (2.3-6.3\%) were the least abundant anthocyanidins, similar to findings reported in previous papers ${ }^{(28,30,31)}$.

Anthocyanidins have been shown to have protective effects in clinical and epidemiological studies, especially against some chronic diseases. In a US breast cancer case-control study, a reduction of all mortality at 6 years of follow-up after a high intake of anthocyanidins and other flavonoids ${ }^{(6)}$ was reported. Concerning CVD, an Italian case-control study observed a significant inverse trend between acute myocardial infarction and anthocyanidin intake, and an OR of 0.45 (95\% CI $0.26,0.78)$ when comparing extreme quintiles $^{(7)}$. However, in two Greek case-control studies no associations were found between anthocyanidin consumption and peripheral arterial occlusive disease ${ }^{(48)}$ or $\mathrm{CHD}^{(49)}$. Indeed, in a recent meta-analysis, Hooper et al. concluded that there were insufficient data from clinical trials to confirm the beneficial effects on $\mathrm{CVD}^{(52)}$. Several epidemiological studies have suggested contradicting results regarding cancer. However, these differences can be explained, in part, by low anthocyanidin bioavailability (less than $5 \%)^{(9)}$ and the wide range of anthocyanidin intakes among studies. Overall, all cancers studied not related to the digestive system (breast, ovarian, prostate, lung, pancreatic, liver, renal cancers, and diffuse and follicular $\beta$-cell lymphomas) have not been significantly associated with anthocyanidin intake $(6,17-20,22-25,53)$. Concerning cancers of the digestive system, when the mean consumption of anthocyanidins is low $(<20 \mathrm{mg} / \mathrm{d})$, non-significant associations have been reported for upper aero-digestive and colorectal cancer, colorectal and oesophageal squamous cell cancer in the Iowa Women's Health Study ${ }^{(19)}$, the Kuopio Ischaemic Heart Disease Risk Factor Study $^{(23)}$ and a US case-control study ${ }^{(11)}$, respectively. However, when their mean intake is high (southern European countries), a protective effect against colorectal, oral cavity, pharyngeal and laryngeal oesophageal cancers comparing extreme quintiles has been observed, although the trend analysis has usually not been significant ${ }^{(12-15)}$. Gastric cancer has only been studied in a Greek case-control study, in which no statistical association with anthocyanidin intake was shown, even though the mean intake was slightly high $(20.4 \mathrm{mg} / \mathrm{d})^{(21)}$. More recently, anthocyanidins have been shown to reach some brain regions after consumption of blueberries in rats ${ }^{(54)}$; therefore they are able to cross the haemato-encephalic barrier. This finding suggests the potential role of anthocyanidins as anti-inflammatory and antioxidant agents against the deleterious effects of ageing and its related neurodegenerative diseases ${ }^{(55)}$ and in improving memory function in older adults ${ }^{(56)}$. Further basic and epidemiological investigation is needed to confirm these potential effects against cancer and cardiovascular and neurodegenerative diseases, but taking into account possible differences among individual anthocyanidins.

To our knowledge, this is a unique study and the largest to date describing anthocyanidin intake across several European countries. However, as not all the EPIC cohorts are representative of the population, the observed level of intake cannot be extrapolated to the general population of each region. Another limitation of the present study is an underestimation of the real anthocyanidin intake, because there are some food items with missing composition data. However, our database was compiled from the most updated flavonoid databases, with only $10 \%$ of missing values. Indeed, the major strength of the present study is the use of a unique and specifically developed FCDB, for that allowed results to be compared across countries. Further underestimation may be due to the omission of dietetic supplements in this analysis. However, there are few consumers of herb or plant 
supplements in the present study (up to $5 \%$ in Denmark, the highest consumer country) ${ }^{(57)}$.

The present study generated data for total and individual anthocyanidin intakes among twenty-seven centres in ten European countries, according to sex, age and some lifestyle factors. Main food sources and differences among European regions were also identified. These descriptive data will be valuable for future aetiological research focused on the relationships between anthocyanidins and chronic diseases.

\section{Acknowledgements}

The present study was carried out with the financial support of the European Commission: Public Health and Consumer Protection Directorate 1993 to 2004; Research Directorate-General 2005; Ligue contre le Cancer; Institut Gustave Roussy; Mutuelle Générale de l'Education Nationale; Institut National de la Santé et de la Recherche Médicale (INSERM) (France); German Cancer Aid; German Cancer Research Centre; German Federal Ministry of Education and Research; Danish Cancer Society; Health Research Fund (FIS) of the Spanish Ministry of Health (RTICC, DR06/0020); the participating regional governments and institutions of Spain; Cancer Research UK; Medical Research Council, UK; the Stroke Association, UK; British Heart Foundation; Department of Health, UK; Food Standards Agency, UK; the Wellcome Trust, UK; Hellenic Ministry of Health; the Stavros Niarchos Foundation; the Hellenic Health Foundation; Italian Association for Research on Cancer; Compagnia San Paolo, Italy; Dutch Ministry of Public Health, Welfare and Sports; Dutch Ministry of Health; Dutch Prevention Funds; LK Research Funds; Dutch ZON (Zorg Onderzoek Nederland); World Cancer Research Fund (WCRF); Swedish Cancer Society; Swedish Scientific Council; Regional Government of Skane, Sweden; Nordforsk - Centre of Excellence Programme. Some authors are partners of ECNIS (Environmental Cancer Risk, Nutrition and Individual Susceptibility), a network of excellence of the 6FP of the European Community. R. Z. R. is thankful for a postdoctoral programme funded by the Fondo de Investigación Sanitaria (FIS; no. CD09/00133) from the Spanish Ministry of Science and Innovation. We thank Raul M. García for developing an application to link the FCDB and the 24-HDR.

R. Z.-R. and C. A. G. designed the research; R. Z.-R. and V. K. conducted the research; R. Z.-R. and L. L.-B. performed the statistical analysis; R. Z.-R. wrote the manuscript; all authors critically reviewed and approved the final manuscript.

The authors are not aware of any conflict of interest.

\section{References}

1. Clifford MN (2000) Anthocyanins - nature, occurrence and dietary burden. I Sci Food Agric 80, 1126-1137.

2. Anderson OM \& Jordheim M (2006) The anthocyanins. In Flavonoids: Chemistry, Biochemistry and Applications, pp. 472-551 [OM Anderson and KR Markham, editors]. Boca Raton, FL: CRC Press/Taylor \& Francis Group.
3. US Departament of Agriculture (2007) USDA Database for the Flavonoid Content of Selected Foods, Release 2.1 ed. Beltsville, MD: USDA.

4. Perez-Jimenez J, Neveu V, Vos F, et al. (2010) Systematic analysis of the content of 502 polyphenols in 452 foods and beverages: an application of the Phenol-Explorer database. J Agric Food Chem 58, 4959-4969.

5. Manach C, Scalbert A, Morand C, et al. (2004) Polyphenols: food sources and bioavailability. Am J Clin Nutr 79, 727-747.

6. Fink BN, Steck SE, Wolff MS, et al. (2007) Dietary flavonoid intake and breast cancer survival among women on Long Island. Cancer Epidemiol Biomarkers Prev 16, 2285-2292.

7. Tavani A, Spertini L, Bosetti C, et al. (2006) Intake of specific flavonoids and risk of acute myocardial infarction in Italy. Public Health Nutr 9, 369-374.

8. Mink PJ, Scrafford CG, Barraj LM, et al. (2007) Flavonoid intake and cardiovascular disease mortality: a prospective study in postmenopausal women. Am J Clin Nutr 85, 895-909.

9. Prior RL \& Wu X (2006) Anthocyanins: structural characteristics that result in unique metabolic patterns and biological activities. Free Radic Res 40, 1014-1028.

10. Wang LS \& Stoner GD (2008) Anthocyanins and their role in cancer prevention. Cancer Lett 269, 281-290.

11. Bobe G, Peterson JJ, Gridley G, et al. (2009) Flavonoid consumption and esophageal cancer among black and white men in the United States. Int J Cancer 125, 1147-1154.

12. Rossi M, Garavello W, Talamini R, et al. (2007) Flavonoids and the risk of oral and pharyngeal cancer: a case-control study from Italy. Cancer Epidemiol Biomarkers Prev 16, $1621-1625$.

13. Garavello W, Rossi M, McLaughlin JK, et al. (2007) Flavonoids and laryngeal cancer risk in Italy. Ann Oncol 18, 1104-1109.

14. Rossi M, Garavello W, Talamini R, et al. (2007) Flavonoids and risk of squamous cell esophageal cancer. Int J Cancer 120, 1560-1564.

15. Rossi M, Negri E, Talamini R, et al. (2006) Flavonoids and colorectal cancer in Italy. Cancer Epidemiol Biomarkers Prev 15, 1555-1558

16. Bobe G, Sansbury LB, Albert PS, et al. (2008) Dietary flavonoids and colorectal adenoma recurrence in the Polyp Prevention Trial. Cancer Epidemiol Biomarkers Prev 17, $1344-1353$

17. Bosetti C, Spertini L, Parpinel M, et al. (2005) Flavonoids and breast cancer risk in Italy. Cancer Epidemiol Biomarkers Prev 14, 805-808.

18. Bosetti C, Rossi M, McLaughlin JK, et al. (2007) Flavonoids and the risk of renal cell carcinoma. Cancer Epidemiol Biomarkers Prev 16, 98-101.

19. Cutler GJ, Nettleton JA, Ross JA, et al. (2008) Dietary flavonoid intake and risk of cancer in postmenopausal women: the Iowa Women's Health Study. Int J Cancer 123, 664-671.

20. Fink BN, Steck SE, Wolff MS, et al. (2007) Dietary flavonoid intake and breast cancer risk among women on Long Island. Am J Epidemiol 165, 514-523.

21. Lagiou P, Samoli E, Lagiou A, et al. (2004) Flavonoids, vitamin $\mathrm{C}$ and adenocarcinoma of the stomach. Cancer Causes Control 15, 67-72.

22. Lagiou P, Rossi M, Lagiou A, et al. (2008) Flavonoid intake and liver cancer: a case-control study in Greece. Cancer Causes Control 19, 813-818.

23. Mursu J, Nurmi T, Tuomainen TP, et al. (2008) Intake of flavonoids and risk of cancer in Finnish men: The Kuopio Ischaemic Heart Disease Risk Factor Study. Int J Cancer 123, 660-663. 
24. Peterson J, Lagiou P, Samoli E, et al. (2003) Flavonoid intake and breast cancer risk: a case-control study in Greece. $\mathrm{BrJ}$ Cancer 89, 1255-1259.

25. Rossi M, Negri E, Lagiou P, et al. (2008) Flavonoids and ovarian cancer risk: a case-control study in Italy. Int J Cancer 123, 895-898.

26. Felgines C, Talavera S, Gonthier MP, et al. (2003) Strawberry anthocyanins are recovered in urine as glucuro- and sulfoconjugates in humans. J Nutr 133, 1296-1301.

27. Hou DX, Yanagita T, Uto T, et al. (2005) Anthocyanidins inhibit cyclooxygenase-2 expression in LPS-evoked macrophages: structure-activity relationship and molecular mechanisms involved. Biochem Pharmacol 70, 417-425.

28. Johannot L \& Somerset SM (2006) Age-related variations in flavonoid intake and sources in the Australian population. Public Health Nutr 9, 1045-1054.

29. Chun OK, Chung SJ \& Song WO (2007) Estimated dietary flavonoid intake and major food sources of US adults. J Nutr 137, 1244-1252.

30. Zamora-Ros R, Andres-Lacueva C, Lamuela-Raventos RM, et al. (2010) Estimation of dietary sources and flavonoid intake in a Spanish adult population (EPIC-Spain). $J \mathrm{Am}$ Diet Assoc 110, 390-398.

31. Ovaskainen ML, Torronen R, Koponen JM, et al. (2008) Dietary intake and major food sources of polyphenols in Finnish adults. J Nutr 138, 562-566.

32. Riboli E \& Kaaks R (1997) The EPIC project: rationale and study design. European Prospective Investigation into Cancer and Nutrition. Int J Epidemiol 26, Suppl. 1, S6-S14.

33. Riboli E, Hunt KJ, Slimani N, et al. (2002) European Prospective Investigation into Cancer and Nutrition (EPIC): study populations and data collection. Public Health Nutr 5, 1113-1124.

34. Slimani N, Kaaks R, Ferrari P, et al. (2002) European Prospective Investigation into Cancer and Nutrition (EPIC) calibration study: rationale, design and population characteristics. Public Health Nutr 5, 1125-1145.

35. Brustad M, Skeie G, Braaten T, et al. (2003) Comparison of telephone vs face-to-face interviews in the assessment of dietary intake by the $24 \mathrm{~h}$ recall EPIC SOFT program - the Norwegian calibration study. Eur J Clin Nutr 57, 107-113.

36. Slimani N, Ferrari P, Ocke M, et al. (2000) Standardization of the 24-hour diet recall calibration method used in the European Prospective Investigation into Cancer and Nutrition (EPIC): general concepts and preliminary results. Eur $J$ Clin Nutr 54, 900-917.

37. Slimani N, Deharveng G, Unwin I, et al. (2007) The EPIC nutrient database project (ENDB): a first attempt to standardize nutrient databases across the 10 European countries participating in the EPIC study. Eur J Clin Nutr 61, 1037-1056.

38. Haftenberger M, Schuit AJ, Tormo MJ, et al. (2002) Physical activity of subjects aged 50-64 years involved in the European Prospective Investigation into Cancer and Nutrition (EPIC). Public Health Nutr 5, 1163-1176.

39. Neveu V, Perez-Jimenez J, Vos F, et al. (2010) PhenolExplorer: an online comprehensive database on polyphenol contents in foods. Database (Oxford) 2010, bap024.

40. Crozier A, Lean MEJ, McDonald MS, et al. (1997) Quantitative analysis of the flavonoid content of commercial tomatoes, onions, lettuces, and celery. J Agric Food Chem 45, 590-595.

41. Hiemori M, Koh E \& Mitchell AE (2009) Influence of cooking on anthocyanins in black rice (Oryza sativa L. japonica var. SBR). J Agric Food Chem 57, 1908-1914.

42. Mulinacci N, Ieri F, Giaccherini C, et al. (2008) Effect of cooking on the anthocyanins, phenolic acids, glycoalkaloids, and resistant starch content in two pigmented cultivars of Solanum tuberosum L. J Agric Food Chem 56, $11830-11837$.

43. Steed LE, Truong VD, Simunovic J, et al. (2008) Continuous flow microwave-assisted processing and aseptic packaging of purple-fleshed sweetpotato purees. J Food Sci 73, $455-462$

44. Xu B \& Chang SK (2008) Total phenolics, phenolic acids, isoflavones, and anthocyanins and antioxidant properties of yellow and black soybeans as affected by thermal processing. J Agric Food Chem 56, 7165-7175.

45. Oliveira C, Amaro LF, Pinho O, et al. (2010) Cooked blueberries: anthocyanin and anthocyanidin degradation and their radical-scavenging activity. J Agric Food Chem 58, 9006-9012.

46. Sieri S, Krogh V, Saieva C, et al. (2009) Alcohol consumption patterns, diet and body weight in 10 European countries. Eur J Clin Nutr 63, Suppl. 4, S81-S100.

47. Agudo A, Slimani N, Ocke MC, et al. (2002) Vegetable and fruit consumption in the EPIC cohorts from 10 European countries. IARC Sci Publ 156, 99-103.

48. Lagiou P, Samoli E, Lagiou A, et al. (2006) Flavonoid classes and risk of peripheral arterial occlusive disease: a casecontrol study in Greece. Eur J Clin Nutr 60, 214-219.

49. Lagiou $\mathrm{P}$, Samoli $\mathrm{E}$, Lagiou A, et al. (2004) Intake of specific flavonoid classes and coronary heart disease - a casecontrol study in Greece. Eur J Clin Nutr 58, 1643-1648.

50. Dilis V \& Trichopoulou A (2010) Antioxidant intakes and food sources in Greek adults. J Nutr 140, 1274-1279.

51. Melby MK, Murashima M \& Watanabe S (2008) Phytochemical intake and relationship to past health history in Japanese women. Biofactors 22, 265-269.

52. Hooper L, Kroon PA, Rimm EB, et al. (2008) Flavonoids, flavonoid-rich foods, and cardiovascular risk: a metaanalysis of randomized controlled trials. Am J Clin Nutr $\mathbf{8 8}, 38-50$.

53. Frankenfeld CL, Cerhan JR, Cozen W, et al. (2008) Dietary flavonoid intake and non-Hodgkin lymphoma risk. $\mathrm{Am} \mathrm{J}$ Clin Nutr 87, 1439-1445.

54. Andres-Lacueva C, Shukitt-Hale B, Galli RL, et al. (2005) Anthocyanins in aged blueberry-fed rats are found centrally and may enhance memory. Nutr Neurosci 8, 111-120.

55. Shukitt-Hale B, Lau FC \& Joseph JA (2008) Berry fruit supplementation and the aging brain. J Agric Food Chem 56, 636-641.

56. Krikorian R, Shidler MD, Nash TA, et al. (2010) Blueberry supplementation improves memory in older adults. J Agric Food Chem 58, 3996-4000.

57. Skeie G, Braaten T, Hjartaker A, et al. (2009) Use of dietary supplements in the European Prospective Investigation into Cancer and Nutrition calibration study. Eur J Clin Nutr 63, Suppl. 4, S226-S238. 